\title{
Hydrogeochemical impact on the karst watershed of the Krka River in Slovenia interpreted by $U$ and $T h$ isotopic composition
}

\author{
LEJA ROVAN ${ }^{1,2}$, SONJA LOJEN ${ }^{1,2}$, TEA ZULIANI ${ }^{1,2}$, \\ BARBARA HORVAT ${ }^{3}$ AND MARKO ŠTROK ${ }^{1,2}$ \\ ${ }^{1}$ Jožef Stefan Institute \\ ${ }^{2}$ Jožef Stefan International Postgraduate School \\ ${ }^{3}$ Slovenian National Building and Civil Engineering Institute \\ Presenting Author: leja.rovan@ijs.si
}

The Krka River in Slovenia is a typical groundwater-fed karstic river with local tufa occurrences. Tufa's characteristics are influenced by the hydrochemical and climate evolution of river systems and can provide information on water-rock interactions, recharge, hydraulic connections, and terrestrial $\mathrm{CO}_{2}$ cycle. The study was focused on better understanding the influence of in-situ processes on elemental and isotopic composition of tufa by examination of spatial patterns of major ion concentrations and $\mathrm{U}$ isotope composition of dissolved elements in river water and with identifying and quantifying the behaviour of $U$ and $T h$ isotopes in surrounding carbonate rocks and tufa.

The investigated area covers the upper $21 \mathrm{~km}$ of the river with 15 consecutive tufa cascades and its tributaries. Samples of river water and tufa were taken in the central part of the stream on the surface of cascades, while bedrock samples were collected based on the spatial distribution of different rock types at the riverbanks. The elemental composition of tufa and bedrock was determined using X-ray fluorescence spectroscopy. U and Th concentrations were determined by triple quadrupole ICP-MS and their isotope ratio measurements were performed with MCICP-MS.

The results provided evidence on the $U$ and Th isotope disequilibrium in river water and its tufa appearance in a lowtemperature range. The differences in $U$ isotope ratios and $U$ concentrations within the watershed of the Krka River are partly due to the different lithology of sub-catchments of the karst aquifer. Moreover, diffused groundwater discharge into the river can also contribute to the variability of the $U$ isotopic composition in river water owing to water-rock interactions and the influence of the alpha recoil effect. Tufa samples display ${ }^{234} \mathrm{U} /{ }^{238} \mathrm{U}$ activity ratios similar to those of the river water, which were higher and relatively constant compared to the bedrock, springs and tributaries. This indicates that the majority of $U$ present in tufa samples is co-precipitated with the carbonate from the river water and can demonstrate its authigenic origin. Additionally, Th and $\mathrm{U}$ concentrations and their isotope ratios in carbonate materials from the study area were also shown to be indicator of carbonate detrital contaminations. 